\title{
Temporal sensitivity of bovine embryos to culture environment after fertilization and the implications for blastocyst quality
}

\author{
P. Lonergan , D. Rizos ${ }^{1}$, J. Kanka², L. Nemcova², A. M. Mbaye², M. Kingston, \\ M. Wade ${ }^{1}$, P. Duffy ${ }^{1}$ and M. P. Boland ${ }^{1}$ \\ ${ }^{1}$ Department of Animal Science and Production and Conway Institute for Biomedical and Biomolecular \\ Research, University College Dublin, Lyons Research Farm, Newcastle, County Dublin, Ireland; \\ and ${ }^{2}$ Institute of Animal Physiology and Genetics, Academy of Sciences of the Czech Republic, \\ 27721 Libechov, Czech Republic
}

\begin{abstract}
The aim of this study was to examine the temporal sensitivity of bovine embryos to culture environment after fertilization to determine which period, if any, is most critical in determining blastocyst quality. Bovine zygotes produced in vitro were divided into six groups and cultured either in vitro (in synthetic oviductal fluid, SOF), in vivo (in the ewe oviduct) or in a combination of both systems. Development to the blastocyst stage, the ability of the blastocysts to withstand cryopreservation and the relative abundance of several gene transcripts were examined. Culture in SOF for either $\mathbf{2}$ or $\mathbf{4}$ days, followed by subsequent culture in the ewe oviduct, resulted in a significantly lower yield of blastocysts than did all other methods, the effect being most marked in embryos that were cultured in SOF for 4 days. In contrast, culture in vivo for the first 2 or 4 days
\end{abstract}

after fertilization followed by culture in vitro did not have such a marked effect on blastocyst development. Blastocysts produced after culture in the oviduct for 6 days had the highest rates of survival over $72 \mathrm{~h}$ after warming $(\mathbf{1 0 0} \%$ survival at $24 \mathrm{~h} ;>95 \%$ survival at $72 \mathrm{~h}$ ). The embryos that spent the last 4 days of culture in vivo also had relatively high rates of survival $(100 \%$ at $24 \mathrm{~h}, 73.7 \%$ at $72 \mathrm{~h})$. Blastocysts produced entirely in SOF had very low rates of survival after vitrification, with $<40 \%$ viable at $24 \mathrm{~h}$ and $<20 \%$ survival at $72 \mathrm{~h}$. Blastocysts derived from embryos that spent the first 2 days in vivo and the last 4 days in vitro had the lowest rates of survival $(6.7 \%)$, whereas those that spent the last 2 days only in SOF had intermediate rates of survival $(\mathbf{4 0 . 6 \% )}$ ). These differences were reflected in the relative abundance of transcripts for the Bax gene.

\section{Introduction}

Although the success of in vitro maturation and fertilization in cattle is high (approximately $80 \%$ ), most cleaved oocytes fail to reach the blastocyst stage (Lonergan et al., 1999a; Rizos et al., 2002a). Using the bovine model, Rizos et al. (2002a) showed that, despite the fact that the major fall off in development occurs between the twocell stage and the blastocyst stage, which would implicate the culture environment after fertilization, it is actually the intrinsic quality of the oocyte itself that is the key factor in determining its ability to reach the blastocyst stage.

McEvoy (2000) stated that attainment of the blastocyst stage is more a reflection of past achievement than a guarantee of future fitness. Therefore, in addition to increasing the success rate of embryo production in vitro (that is, the number of oocytes that develop to the blastocyst stage), it is essential that the embryos that do reach this stage in vitro are of the highest quality possible to ensure optimal rates of pregnancy after transfer. The quality

Email: pat.lonergan@ucd.ie of blastocysts produced in vitro continually lags behind that of blastocysts produced in vivo and this can be linked to differences between them. Embryos produced in vitro tend to have darker cytoplasm and a lower buoyant density (Pollard and Leibo, 1994) as a consequence of their higher lipid content (Abd El Razek et al., 2000), a more fragile zona pellucida (Duby et al., 1997), reduced expression of intercellular communication devices (Boni et al., 1999), and a higher incidence of chromosome abnormalities (Viuff et al., 1999; Slimane et al., 2000) than do their in vivo-produced counterparts.

Within in vitro systems, modifications of the embryo culture environment after fertilization can have profound effects on gene expression in the embryo (Wrenzycki et al., 1999, 2001; Rief et al., 2002; Rizos et al., 2002b, 2003) that, in turn, can have serious implications for the normality of the blastocyst. By culturing in vitroproduced bovine zygotes in vivo in ewe oviduct it has been shown that it is possible to increase markedly the quality of the resulting blastocysts, measured in terms of cryotolerance, to a level similar to that of embryos produced entirely in vivo (Enright et al., 2000; Rizos et al., 2002a). Conversely, the culture of in vivo-produced 
bovine zygotes in vitro resulted in blastocysts of low cryotolerance (Rizos et al., 2002a), indicating that the culture period after fertilization (from day 1 to day 7 ) is the most critical period for determining blastocyst quality. The detrimental effects of culture under suboptimal conditions in vitro are mediated through modifications of gene expression in the embryo. These detrimental effects can be seen as blastocysts incapable of withstanding cryopreservation or establishing a pregnancy, or, as has been shown in ruminants, the production of offspring of abnormal size (Young et al., 1998). Production of offspring of abnormal size is directly linked to in vitro culture after fertilization (McEvoy et al., 1998) and has very serious implications for human assisted reproduction, in which there is a trend towards transferring blastocyst stage embryos instead of early stage embryos, which necessitates a longer period of culture in vitro in potentially detrimental conditions (Gardner and Lane, 1997; Gardner et al., 2000).

Several major developmental events occur during the 6-day window between zygote and blastocyst formation in cattle. These include the first cleavage division, the timing of which is of critical importance in determining the subsequent development of the embryo (Lonergan et al., 1999), the activation of the embryonic genome at the 816-cell stage (Camous et al., 1986; Kopecny et al., 1989; Memili and First, 2000), compaction of the morula on day 5 , which involves the establishment of the first intimate cell-cell contacts in the embryo (Boni et al., 1999), and blastocyst formation on days $6-7$, involving the differentiation of two types of cell, the trophectoderm and the inner cell mass (Watson, 1992). Clearly, any modifications of the culture environment, which could affect any, or all, of these processes, could have a major effect on the quality of the embryo. The aim of the present study was to isolate these developmental events, using the ewe oviduct model, and to identify the period of culture after fertilization (that is, the period of early embryo development from day 1 to day 7) that is most critical in determining blastocyst quality, measured in terms of the blastocyst cryotolerance and the relative abundance of certain gene transcripts.

\section{Materials and Methods}

\section{Experimental design}

The design of Expt 1 is shown (Fig. 1). Zygotes produced in vitro were divided into six groups and cultured either in vitro (in synthetic oviduct fluid (SOF), which is known to produce poor quality blastocysts), in vivo (in ewe oviduct, which is known to produce excellent quality blastocysts) or in a combination of both systems, according to the scheme outlined (Fig. 1). A group of in vivo-derived blastocysts from superovulated heifers were used as a control. The groups used were: group 1: culture in SOF for 6 days; group 2: culture in SOF for
2 days followed by culture in ewe oviduct for 4 days; group 3: culture in SOF for 4 days followed by culture in ewe oviduct for 2 days; group 4: culture in ewe oviduct for 2 days followed by culture in SOF for 4 days; group 5: culture in ewe oviduct for 4 days followed by culture in SOF for 2 days; group 6: culture in ewe oviduct for 6 days; and group 7: in vivo-produced blastocysts after superovulation and embryo recovery.

On the basis of the results of Expt 1, a second experiment was performed to confirm the poor development observed in groups 2 and 3. Presumptive zygotes were cultured in: (i) SOF for 6 days (group 1 from Expt 1); or (ii) SOF for 4 days followed by ewe oviduct for 2 days (group 3 from Expt 1). In addition, a sham group of embryos was removed from the incubator, transported to the surgery alongside group 3 and then replaced in the incubator in SOF.

\section{Oocyte collection and in vitro maturation (IVM)}

Cumulus-oocyte complexes (COCs) were obtained by aspirating follicles from the ovaries of slaughtered heifers. After four washes in PBS supplemented with $36 \mu \mathrm{g}$ pyruvate $\mathrm{ml}^{-1}, 50 \mu \mathrm{g}$ gentamycin $\mathrm{ml}^{-1}$ and $0.5 \mathrm{mg} \mathrm{BSA} \mathrm{m}^{-1}$ (Sigma, St Louis, MO), groups of up to 50 COCs were placed in $500 \mu \mathrm{l}$ maturation medium in four-well dishes (Nunc, Roskilde) and cultured for $24 \mathrm{~h}$ at $39^{\circ} \mathrm{C}$ under an atmosphere of $5 \% \mathrm{CO}_{2}$ in air with maximum humidity. The maturation medium was TCM-199 supplemented with $10 \%$ fetal calf serum (FCS) and $10 \mathrm{ng}$ epidermal growth factor (EGF) $\mathrm{ml}^{-1}$ (Lonergan et al., 1996).

\section{Sperm preparation and in vitro fertilization (IVF)}

For IVF, COCs were washed four times in PBS and then in fertilization medium before they were transferred in groups of up to 50 into four-well dishes containing $250 \mu \mathrm{l}$ fertilization medium (Tyrode's medium with $25 \mathrm{mmol}$ bicarbonate $\mathrm{I}^{-1}, 22 \mathrm{mmol}$ sodium lactate $\mathrm{I}^{-1}$, $1 \mathrm{mmol}$ sodium pyruvate $\mathrm{I}^{-1}$ and $6 \mathrm{mg}$ fatty acid-free BSA $\mathrm{ml}^{-1}$ ). In addition, $10 \mu \mathrm{g}$ heparin-sodium salt $\mathrm{ml}^{-1}$ (184 U mg ${ }^{-1}$ heparin; Calbiochem, San Diego, CA) was added. Motile spermatozoa were obtained by centrifugation of frozen-thawed semen (Dairygold A.I. Station, Mallow) on a discontinuous Percoll (Pharmacia, Uppsala) density gradient $(2.5 \mathrm{ml} 45 \%$ (v/v) Percoll over $2.5 \mathrm{ml} 90 \%(\mathrm{v} / \mathrm{v})$ Percoll) at $700 \mathrm{~g}$ for $8 \mathrm{~min}$ at room temperature. Viable spermatozoa collected at the bottom of the $90 \%$ fraction were washed in Hepes-buffered Tyrode's medium and pelleted by centrifugation at $100 \mathrm{~g}$ for $5 \mathrm{~min}$. The spermatozoa were counted in a haemocytometer and diluted in the appropriate volume of fertilization medium to give a concentration of $2 \times 10^{6}$ spermatozoa $\mathrm{ml}^{-1}$. A $250 \mu \mathrm{l}$ aliquot of this suspension was added to each fertilization well to obtain a final concentration of $1 \times 10^{6}$ spermatozoa $\mathrm{ml}^{-1}$. The plates 
SOF 6 days
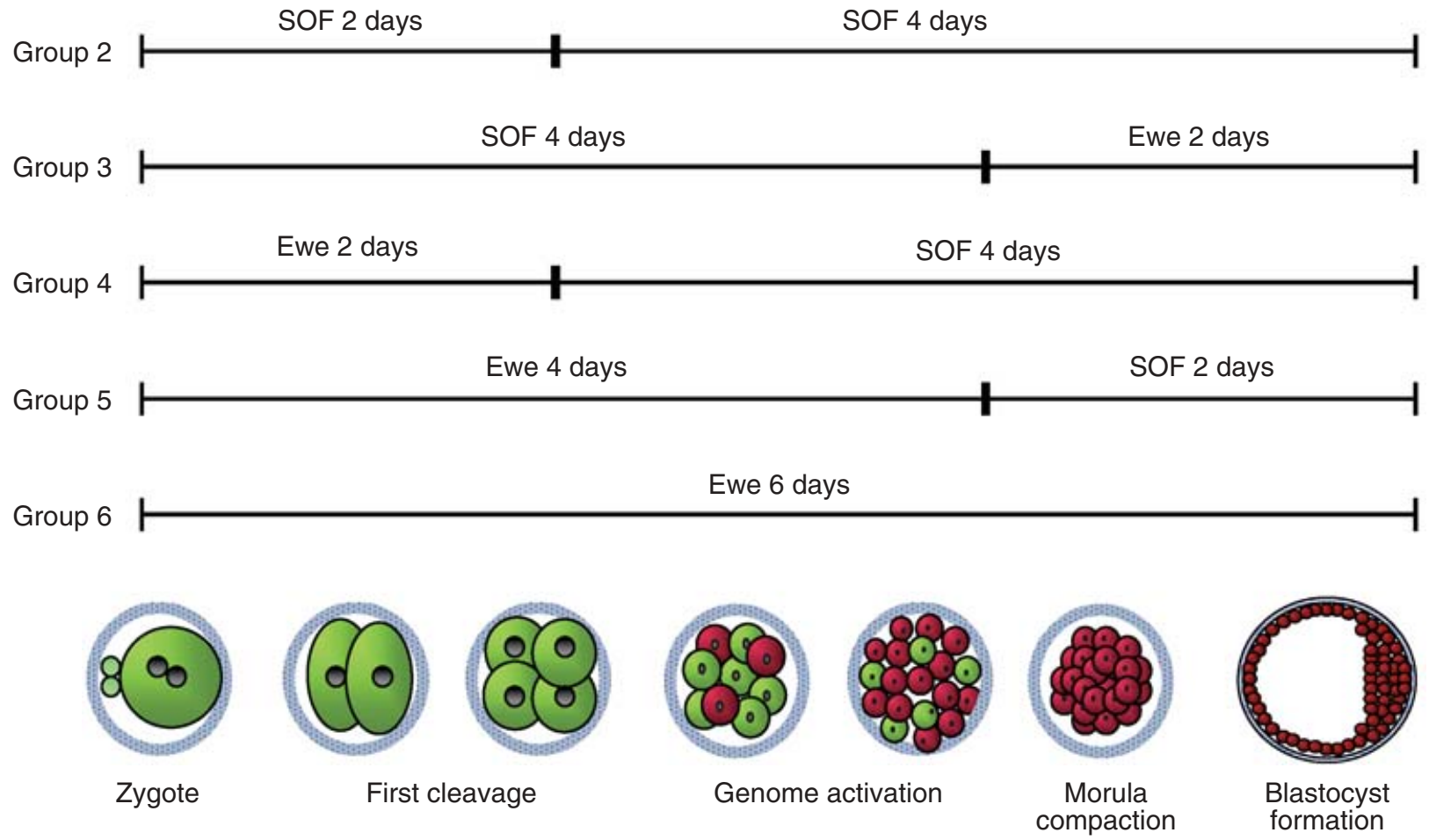

Fig. 1. Design of Expt 1. Blastocysts were produced after culture of in vitro-matured-in vitro-fertilized zygotes in: group 1: synthetic oviductal fluid (SOF) for 6 days; group 2: SOF for 2 days followed by culture in ewe oviduct for 4 days; group 3: SOF for 4 days followed by culture in ewe oviduct for 2 days; group 4: ewe oviduct for 2 days followed by culture in SOF for 4 days; group 5: ewe oviduct for 4 days followed by culture in SOF for 2 days; or group 6: ewe oviduct for 6 days. An additional group of blastocysts (group 7) was derived in vivo after superovulation and embryo recovery.

were incubated for $20 \mathrm{~h}$ at $39^{\circ} \mathrm{C}$ under an atmosphere of $5 \% \mathrm{CO}_{2}$ in air with maximum humidity. Semen from the same bull was used for all experiments.

\section{Embryo culture after fertilization}

At approximately $20 \mathrm{~h}$ after insemination, presumptive zygotes were denuded by gentle vortexing and washed four times in PBS before they were randomly assigned to treatment. For in vitro culture (IVC), zygotes were transferred to $25 \mu \mathrm{l}$ culture droplets of SOF (25 embryos per droplet; Lonergan et al., 1999b) under mineral oil (Sigma). FCS (10\%) was added $24 \mathrm{~h}$ after placement in culture. The dishes were incubated in an atmosphere of $5 \% \mathrm{CO}_{2}, 5 \% \mathrm{O}_{2}$ and $90 \% \mathrm{~N}_{2}$ at $39^{\circ} \mathrm{C}$.

For in vivo culture, presumptive zygotes or embryos produced after IVM-IVF were surgically transferred to ligated ewe oviducts (approximately 100 per oviduct). Two ewes (that is, four oviducts) were used per group. Ewes were used without regard to stage of cycle; however, a vaginal progestagen pessary was inserted to prevent the ewes from entering oestrus during the period of transfer and recovery. Transfer was performed at $20 \mathrm{~h}$ after insemination (groups 4, 5 and 6), 3 days after insemination (group 2) or 5 days after insemination (group 3). Embryos were recovered from the ewes at day 3 after insemination (group 4), day 5 after insemination (group 5) or day 7 after insemination (groups 2, 3 and 6) by flushing the oviduct with $20 \mathrm{ml} \mathrm{PBS}$. For some groups, the embryos were placed in SOF $+10 \%$ FCS for further culture (see Fig. 1).

Cleavage was assessed at $48 \mathrm{~h}$ after insemination (or at recovery from ewe oviduct) and blastocyst development was recorded on days 6-8 (day $0=$ day of IVF) and expressed as a fraction of the total number of embryos recovered. Day 7 blastocysts were used for the cryotolerance and transcript abundance studies. The remaining embryos were maintained in vitro until day 8 .

\section{In vivo production of blastocysts}

In vivo-derived blastocysts collected from heifers were used as a control. The protocol used for the in vivo production of embryos was as described by Rizos et al. 
Table 1. Specific semi-quantitative RT-PCR conditions

\begin{tabular}{|c|c|c|c|c|}
\hline cDNAs & RT-PCR primers & $\begin{array}{c}\text { Annealing } \\
\text { temperature }\left({ }^{\circ} \mathrm{C}\right)\end{array}$ & $\begin{array}{l}\text { Number of embryos } \\
\text { per RT-PCR }\end{array}$ & $\begin{array}{l}\text { Number of } \\
\text { PCR cycles }\end{array}$ \\
\hline$\beta$-actin & $\begin{array}{l}\text { 5'-GAGAAGCTCTGCTACGTCG } \\
\text { 3'-CCAGACAGCACCGTGTTGG }\end{array}$ & 60 & 1 & 29 \\
\hline Bax & $\begin{array}{l}\text { 5'-TGCAGAGGATGATCGCAGCTGTG } \\
\text { 3'-CCAATGTCCAGCCCATCATGGTC }\end{array}$ & 59 & 1 & 29 \\
\hline L37 & $\begin{array}{l}\text { 5'-TCATCGTTTGGAAAGCGTCGGAATA } \\
\text { 3'-GCTCGCTTGGGTTTAGGTGTTGTTC }\end{array}$ & 59 & 1 & 25 \\
\hline S3a & $\begin{array}{l}\text { 5'-TTGGACTGGTGGCTCGTATC } \\
\text { 3'-AGATCCGCGAGAAGATGATG }\end{array}$ & 59 & 1 & 28 \\
\hline
\end{tabular}

(2002a). Beef cross heifers were synchronized using a controlled internal drug releasing (CIDR) device (InterAg, Hamilton) for 8 days. At day 3 before CIDR removal, the heifers received $2 \mathrm{ml}(15 \mathrm{mg})$ of prostaglandin $F_{2 \alpha}$ analogue (PG; Prosolvin; Intervet, Dublin). The heifers were checked for standing oestrus (= day 0$)$. The dominant follicle was ablated by transvaginal aspiration on day 8 of the oestrous cycle. Beginning on day 10, the animals were superovulated with a total of $180 \mathrm{mg} \mathrm{FSH}$ (Folltropin; Vetrepharm Canada Inc., London, ON) given as injections twice a day over 4 days on a decreasing dose schedule. Luteolysis was induced with $15 \mathrm{mg}$ PG given on day 12 . Heifers were inseminated with frozenthawed semen at $48 \mathrm{~h}$ and $60 \mathrm{~h}$ after PG injection. The same semen batch as was used for IVF was used for artificial insemination. Day 7 embryos were recovered by non-surgical flushing at day 9 after PG administration.

\section{Blastocyst vitrification}

The ability of the blastocyst to withstand cryopreservation was used as a tool to assess quality (Rizos et al., 2001, 2002a, 2003). Blastocysts were vitrified using the open pulled straw (OPS) method described by Vajta et al. (1998) in a final solution containing 20\% (v/v) ethylene glycol and 20\% (v/v) DMSO. Warmed blastocysts were cultured in $25 \mu \mathrm{l}$ droplets of M199+10\% FCS in the presence of a granulosa cell monolayer (Rizos et al., 2001) and were examined at 24,48 and $72 \mathrm{~h}$ after warming. Survival was defined as re-expansion of the blastocoel and its maintenance for 24,48 and $72 \mathrm{~h}$, respectively. The rate of hatching was also recorded and was expressed as a percentage of the embryos surviving at $72 \mathrm{~h}$ after warming.

\section{RNA extraction from blastocysts for analysis of transcript abundance}

Total RNA was prepared from each group of pools of ten blastocysts using an RNeasy mini column (Qiagen, Hilden) following the manufacturer's instructions. The blastocysts were washed three times in PBS and immediately snap-frozen in a minimal volume (approximately
$2 \mu \mathrm{l})$ of PBS in liquid nitrogen and stored at $-80^{\circ} \mathrm{C}$ until use. After lysis of blastocysts in lysis buffer (Qiagen) and isolation on the Qiagen minicolumn, the RNA (isolated from the group of ten blastocysts) was resuspended in $30 \mu \mathrm{l}$ RNase-free water and stored at $-80^{\circ} \mathrm{C}$.

\section{Semi-quantitative $R T-P C R$}

Cell death inducer gene (Bax) and ribosomal proteins S3a and L37 were selected for determining the relative abundance of transcripts in the blastocysts derived from the different groups. Bax belongs to the group of preapoptotic proteins that initiate mitochondrial dysfunction and localize to the endoplasmic reticulum (Scorano et al., 2003). Ribosomal protein S3a is essential for initiation of translation (Westermann et al., 1981; Cramton and Laski, 1994), its expression prevents apoptosis (Song et al., 2002), and up- and downregulation of S3a expression, coordinated in sequence, can induce apoptosis (Naora et al., 1998a). In contrast, L37 ribosomal protein gene was chosen because L37 is expressed constitutively even during the transition from quiescence to active proliferation or terminal differentiation (Su and Bird, 1995). The $\beta$-actin gene expression was used as an internal standard (Rizos et al., 2003).

The platinum quantitative RT-PCR ThermoScript onestep system (Life Technologies, Rockville, MD) was used for multiplication of RNA molecules. This system takes advantage of high temperature reverse transcription by ThermoScript plus reverse transcriptase directly coupled to an automatic hot-start PCR. The equivalent of one blastocyst ( $3 \mu$ l RNA sample) was used in RT-PCR for each transcript according to the manufacturer's instructions. RT-PCR was performed with specific primer pairs (Table 1) within a previously determined linear range of amplification. The PCR reaction volume was $25 \mu \mathrm{l}$ and consisted of ThermoScript Reaction Mix (Life Technologies), sense primer $\left(0.2 \mu \mathrm{mol} \mathrm{I}^{-1}\right)$, antisense primer $\left(\mu \mathrm{mol} \mathrm{I}{ }^{-1}\right)$, RNasine (20 U; Promega, Madison, WI) and ThermoScript plus/platinum Taq enzyme mix (Life Technologies). RT-PCR was performed as follows: cDNA synthesis at $60^{\circ} \mathrm{C}$ for $30 \mathrm{~min}$, pre-denaturation at $95^{\circ} \mathrm{C}$ for $5 \mathrm{~min}$, followed by a specific number of cycles of 
Table 2. Effect of culturing in vitro-produced bovine zygotes in vitro, in synthetic oviductal fluid (SOF), in vivo in ewe oviduct or in a combination of both systems, on cleavage and development to the blastocyst stage

\begin{tabular}{lcccccc}
\hline & $\begin{array}{c}\text { Number of } \\
\text { zygotes or } \\
\text { embryos } \\
\text { Culture system }\end{array}$ & $\begin{array}{c}\text { Number of } \\
\text { embryos } \\
\text { transferred }\end{array}$ & $\begin{array}{c}\text { Number of } \\
\text { embryos } \\
\text { cleaved }(\%)\end{array}$ & & & \multicolumn{2}{c}{ Blastocyst yield } \\
\cline { 5 - 7 } SOF 6 days & 354 & - & $292(82.5)$ & $55(15.5)$ & $94(26.5)^{\mathrm{ab}}$ & $107(30.2)^{\mathrm{a}}$ \\
SOF 2 days + ewe 4 days* & 400 & $318(79.5)$ & $329(82.2)$ & - & $12(3.8)^{\mathrm{c}}$ & $26(8.2)^{\mathrm{b}}$ \\
SOF 4 days + ewe 2 days & 334 & $135(40.4)$ & $267(79.9)$ & - & $0(0)^{\mathrm{d}}$ & $0(0)^{\mathrm{c}}$ \\
Ewe 2 days + SOF 4 days & 400 & $327(81.7)$ & $257(78.6)$ & $36(11.0)$ & $66(20.2)^{\mathrm{a}}$ & $74(22.6)^{\mathrm{a}}$ \\
Ewe 4 days + SOF 2 days & 400 & $274(68.5)$ & - & $32(11.7)$ & $85(31.0)^{\mathrm{b}}$ & $89(32.5)^{\mathrm{a}}$ \\
Ewe 6 days & 400 & $298(74.5)$ & - & - & $72(24.2)^{\mathrm{ab}}$ & $86(28.9)^{\mathrm{a}}$ \\
Significance & & & $\mathrm{ns}$ & $\mathrm{ns}$ & $P<0.05$ & $P<0.05$ \\
\hline
\end{tabular}

*SOF 2 days + ewe 4 days: zygotes were cultured for 2 days in synthetic oviductal fluid followed by 4 days in ewe oviduct.

${ }^{a-d}$ Values in the same column with different superscripts are significantly different $(P<0.05)$. ns: not significant.

denaturation $\left(95^{\circ} \mathrm{C}\right.$ for $\left.30 \mathrm{~s}\right)$, annealing $\left(59\right.$ or $60^{\circ} \mathrm{C}$ for $30 \mathrm{~s})$, extension $\left(72^{\circ} \mathrm{C}\right.$ for $\left.45 \mathrm{~s}\right)$, and final extension at $72^{\circ} \mathrm{C}$ for $5 \mathrm{~min}$. Products of the semi-quantitative specific RT-PCR $(10 \mu \mathrm{l})$ were separated by electrophoresis on a $1.5 \%(\mathrm{w} / \mathrm{v})$ agarose gel, blotted on Hybond $\mathrm{N}+$ nylon membrane (Amersham Biotech, Little Chalfont) and hybridized with specific radioactive probes $\left({ }^{32} \mathrm{P}\right)$ diluted in a Church buffer (Church and Gilbert, 1984) at $65^{\circ} \mathrm{C}$ overnight. The membranes were washed under stringent conditions twice with $2 \times$ SSC, $0.1 \%(\mathrm{w} / \mathrm{v})$ SDS buffer at $65^{\circ} \mathrm{C}$ for $15 \mathrm{~min}$ and once with $0.2 \times \mathrm{SSC}, 0.1 \%(\mathrm{w} / \mathrm{v})$ SDS buffer at $65^{\circ} \mathrm{C}$ for $15 \mathrm{~min}$. Hybridized signals were detected in BAS 2500 (Fuji, Kanagawa) and quantified using the AIDA programme (Raytest, Straubenhardt). Negative control tubes were always prepared in which RNA was omitted.

\section{Statistical analysis}

Differences in the rate of cleavage and the proportion of immature oocytes reaching the blastocyst stage, and rates of blastocyst survival after vitrification and warming were compared using chi-squared analysis. The data of semi-quantitative mRNA expression were analysed using SigmaStat version 3.00 (Jandel Scientific, San Rafael, CA) software package. One way repeated measures ANOVA (followed by pairwise multiple comparison procedures, Holm-Sidak method) was used for the analysis of differences in mRNA expression. $P<0.05$ was considered significant.

\section{Results}

\section{Development}

Rates of embryo recovery and developmental data from Experiment 1 are shown (Table 2). The mean rate of recovery of embryos from ewe oviduct was $69.9 \%$ (1352/ 1934). There were no differences in rates of cleavage between any of the groups. Similarly, blastocyst yield on day 6 was not different between the groups in which it was assessed.

Consistent with the authors' previous observations, there was no difference in blastocyst yield when culture took place either in vitro or in vivo for the entire period (30.2 versus $28.9 \%$, respectively). Culture in SOF for either 2 or 4 days, followed by subsequent culture in ewe oviduct, resulted in a significantly lower yield of blastocysts than did all other treatments, the effect being most marked in the group of embryos cultured in SOF for 4 days, in which all embryos were degenerated on recovery. In contrast, culture in vivo for the first 2 or 4 days after fertilization followed by culture in vitro did not have such a marked effect on blastocyst development (Table 2).

The results of Expt 2 (Table 3) confirmed those of Expt 1. There were no differences in the rate of cleavage between the three groups of embryos (81.4-85.0\%). Culture in SOF for 4 days followed by culture in ewe oviduct for 2 days resulted in no blastocyst development despite the fact that embryos from the sham transfer group developed as well as the control embryos.

\section{Cryotolerance}

In terms of embryo quality, as measured by cryotolerance, blastocysts produced in vivo (control), as well as those produced after culture in the oviduct for 6 days, had the highest rates of survival over $72 \mathrm{~h}$ after warming ( $100 \%$ survival at $24 \mathrm{~h},>95 \%$ survival at $72 \mathrm{~h}$; Fig. 2 ). The embryos that spent the last 4 days of culture in vivo also had relatively high rates of survival $(100 \%$ at $24 \mathrm{~h}$, $73.7 \%$ at $72 \mathrm{~h}$ ). Consistent with previous observations, blastocysts produced entirely in SOF had very low rates of survival after vitrification, with $<40 \%$ viable at $24 \mathrm{~h}$ and $<20 \%$ survival at $72 \mathrm{~h}$. Blastocysts derived from embryos that spent the first 2 days in vivo and the last 4 days in vitro had the lowest rates of survival $(6.7 \%)$, whereas those that spent the last 2 days only in SOF had intermediate rates of survival $(40.6 \%)$. 
Table 3. Effect of culturing in vitro-produced bovine zygotes in vitro, in synthetic oviductal fluid (SOF), in vivo in ewe oviduct or in a combination of both systems, on cleavage and development to the blastocyst stage

\begin{tabular}{lcccccc}
\hline & $\begin{array}{c}\text { Number of } \\
\text { zygotes or } \\
\text { embryos } \\
\text { Culture system }\end{array}$ & $\begin{array}{c}\text { Number of } \\
\text { embryos } \\
\text { transferred }\end{array}$ & $\begin{array}{c}\text { Number of } \\
\text { embryos } \\
\text { recovered }(\%)\end{array}$ & & & \multicolumn{2}{c}{ Blastocyst yield } \\
\hline SOF 6 days & 43 & - & $35(81.4)$ & $4(9.3)^{\mathrm{a}}$ & $8(18.6)^{\mathrm{a}}$ & $9(20.9)^{\mathrm{a}}$ \\
SOF 4 days + ewe 2 days* & 147 & $132(40.4)$ & $125(85.0)$ & $0(0)^{\mathrm{b}}$ & $0(0)^{\mathrm{b}}$ & $0(0)^{\mathrm{b}}$ \\
Sham transfer & 100 & $100(100)$ & $82(82.0)$ & $14(14.0)^{\mathrm{a}}$ & $27(27.0)^{\mathrm{a}}$ & $29(29.0)^{\mathrm{a}}$ \\
Significance & & & $\mathrm{ns}$ & $P<0.001$ & $P<0.001$ & $P<0.001$ \\
\hline
\end{tabular}

*SOF 4 days + ewe 2 days: culture for 4 days in synthetic oviductal fluid followed by 2 days in ewe oviduct.

${ }^{a b}$ Values in the same column with different superscripts are significantly different $(P<0.001)$. ns: not significant.

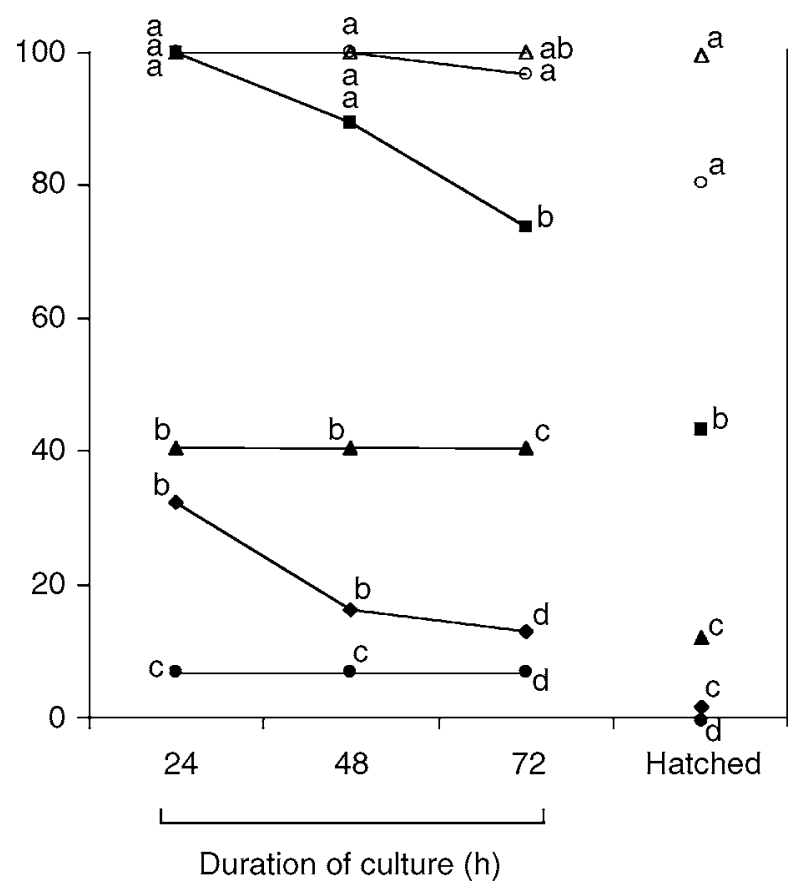

Fig. 2. Survival of bovine blastocysts after vitrification and warming and subsequent culture for $72 \mathrm{~h}$. Blastocysts were produced after culture of in vitro-matured-in vitro-fertilized zygotes in: group 1

$(\bullet)$ : synthetic oviductal fluid (SOF) for 6 days $(n=31)$; group 2 (ם): SOF for 2 days followed by culture in ewe oviduct for 4 days $(n=19)$; group $4(\mathbf{0})$ : ewe oviduct for 2 days followed by culture in SOF for 4 days $(n=30)$; group $5(\mathbf{\Lambda})$ : ewe oviduct for 4 days followed by culture in SOF for 2 days $(n=32)$; or group $6(\bigcirc)$ : ewe oviduct for 6 days $(n=31)$. An additional group of blastocysts (group $7 ; \triangle$ ) was derived in vivo after superovulation and embryo recovery. An additional group of blastocysts (group 7) was derived in vivo after superovulation and embryo recovery $(n=6)$. (No blastocysts were available from Group 3: culture in SOF for 4 days followed by culture in the ewe oviduct for 2 days). ${ }^{a-d}$ Values with different superscripts at the same time-point differ significantly $(P<0.05)$

These differences in rates of blastocyst survival were reflected in the proportion of blastocysts hatching by $72 \mathrm{~h}$ after vitrification and warming. All of the blastocysts produced in vivo and $>80 \%$ of those cultured in ewe oviduct for 6 days hatched, compared with only $3.2 \%$ of those cultured in SOF for 6 days. Culture in vivo for the last 4 days resulted in significantly higher rates of hatching $(42.1 \%)$ compared with culture in SOF for the same period $(0 \%)$.

\section{Relative abundance of transcripts}

The amount of $\beta$-actin amplification products obtained from the different experimental groups was very similar with minimal variations quantified (Fig. 3). Thus, $\beta$-actin amplification was used as an internal standard control of RT-PCR. Values for Bax (Fig. 4), L37 ribosomal protein (Fig. 5) and S3a ribosomal protein (Fig. 6) expression were obtained by dividing the value for the specific product by the corresponding $\beta$-actin value; the largest sample signal was then set at $100 \%$.

High transcript abundance for Bax correlated with longer periods of culture in vitro in SOF. Bax mRNA was expressed strongly in blastocysts produced in vitro in SOF (Fig. 4); transcript abundance was significantly higher than after culture in the ewe oviduct for 6 days (group 6) or in embryos produced entirely in vivo. There was no difference in transcript abundance between blastocysts produced by culture for 6 days in ewe oviduct or those derived in vivo.

Transcripts for the ribosomal gene L37 were expressed strongly in all experimental groups. There was no correlation between culture environment and mRNA expression. L37 behaved as a housekeeping gene.

S3a mRNA was expressed weakly in the blastocysts of all experimental groups. The variation in expression was high even among samples in individual groups. There was no correlation between culture environment and expression.

\section{Discussion}

The main findings of the present study were: (i) blastocysts produced after culture of in vitro-matured/in vitrofertilized zygotes in ewe oviduct are of superior quality to 


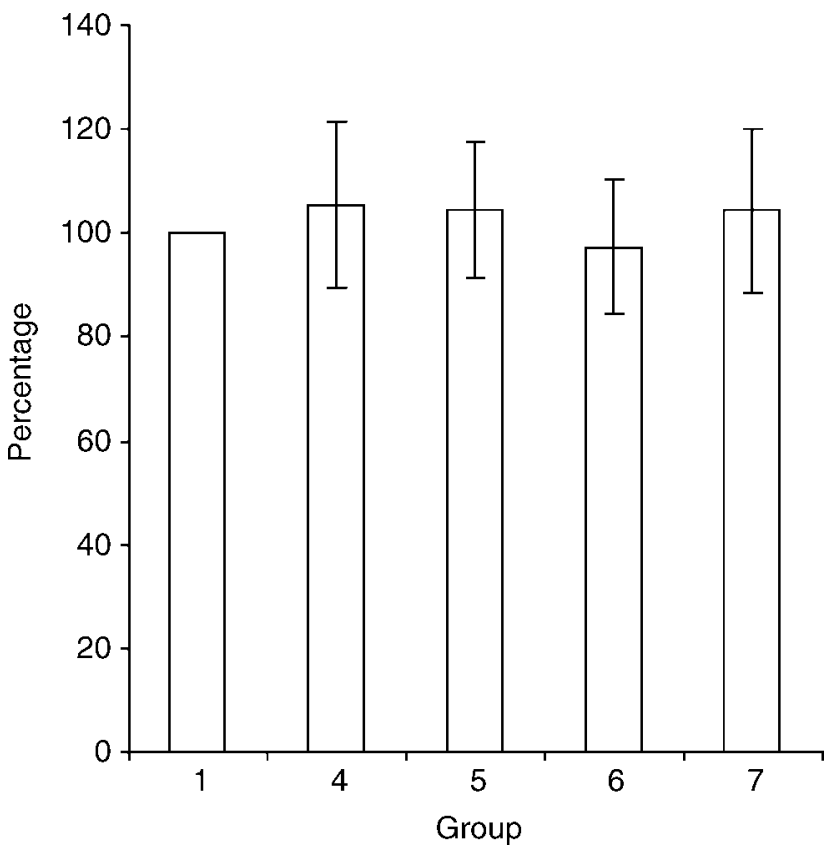

Fig. 3. Semi-quantitative RT-PCR of bovine $\beta$-actin. RT-PCRs were performed with the equivalent of one blastocyst from each group. Group 1: synthetic oviductal fluid (SOF) for 6 days; group 4: ewe oviduct for 2 days followed by culture in SOF for 4 days; group 5 : ewe oviduct for 4 days followed by culture in SOF for 2 days; group 6: ewe oviduct for 6 days; and group 7: blastocysts were derived in vivo after superovulation and embryo recovery. The mean \pm SD was obtained from three independent RT-PCRs from different batches of blastocysts. The values obtained for group 1 were set at $100 \%$ and those of other groups were expressed relative to this value. There were no significant differences between groups.

those produced after culture in vitro; (ii) such blastocysts show temporal sensitivity in terms of quality depending on both the duration and the timing of culture in an optimal (in vivo) or suboptimal (in vitro) environment; and (iii) the temporal sensitivities as manifested in terms of cryotolerance are reflected in the patterns of gene expression.

Comparative studies on the effects of various media constituents have generally focused on the percentage of embryos that develop to the blastocyst stage. Although it is reasonable to use such developmental parameters as markers of the efficacy of culture systems, it is likely that in some cases the effects of a given culture method may not manifest themselves during the relatively short period of in vitro culture, or that the effect may be on less tangible parameters than blastocyst yield, such as blastocyst quality. For this reason, we have combined measurement of developmental competence (cleavage and blastocyst development) with two qualitative measures, namely the ability of the blastocyst to withstand cryopreservation (Rizos et al., 2002a,c, 2003) and the pattern of gene expression within the blastocyst (Rizos et al., 2002b, 2003).

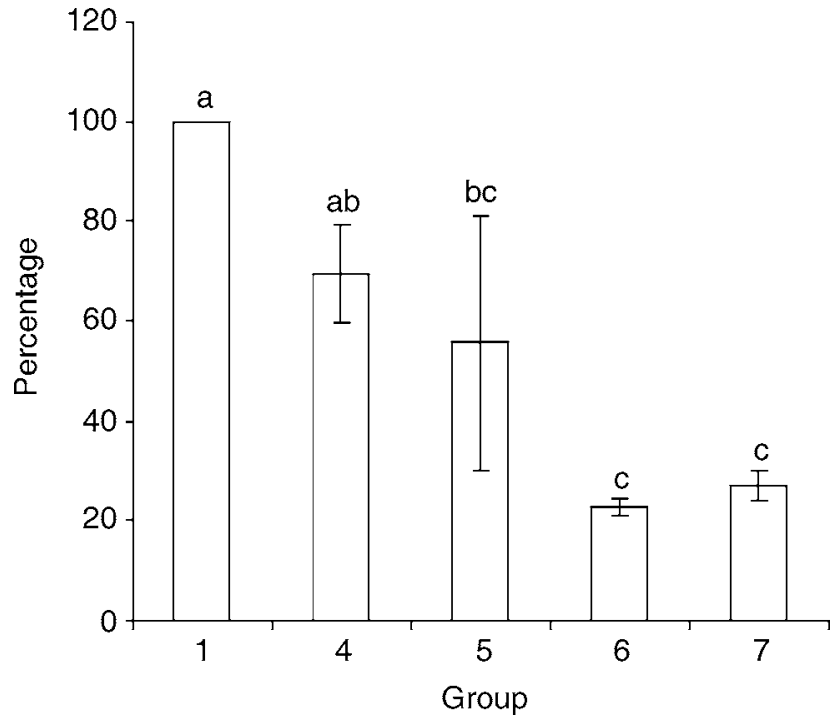

Fig. 4. Semi-quantitative RT-PCR of bovine Bax. RT-PCRs were performed with the equivalent of one blastocyst from each group. Group 1: synthetic oviductal fluid (SOF) for 6 days; group 4: ewe oviduct for 2 days followed by culture in SOF for 4 days; group 5: ewe oviduct for 4 days followed by culture in SOF for 2 days; group 6: ewe oviduct for 6 days; and group 7: blastocysts were derived in vivo after superovulation and embryo recovery. The mean \pm SD was obtained from three independent RT-PCRs from different batches of blastocysts. The values for Bax were divided by the corresponding $\beta$-actin value (housekeeping gene, internal standard) and expressed relative to the highest sample signal set at $100 \%{ }^{a-c}$ Bars with different superscripts are significantly different $(P<0.05)$.

In agreement with previous observations (Enright et al., 2000; Rizos et al., 2002a), there was no difference in blastocyst yield between culture in SOF for 6 days versus culture in vivo for 6 days. In terms of blastocyst quality, the results were also consistent with previous observations; culture in ewe oviduct for 6 days resulted in blastocysts of high quality with cryotolerance similar to that of in vivo-derived blastocysts. In contrast, culture in SOF for 6 days resulted in blastocysts of low cryotolerance, with $<40 \%$ surviving at $24 \mathrm{~h}$ after warming, $<20 \%$ surviving at $72 \mathrm{~h}$ and only a very low percentage hatching $(3.2 \%)$.

The results of the present study indicate that bovine embryos show temporal sensitivity to the culture environment after fertilization, which is manifested in terms of the quality of the blastocysts produced. In terms of embryo quality, as measured by cryotolerance, blastocysts produced in vivo (control), as well as those produced after culture in oviduct for 6 days, had the highest rates of survival over $72 \mathrm{~h}$ after warming $(100 \%$ survival at $24 \mathrm{~h},>95 \%$ survival at $72 \mathrm{~h}$ ). The embryos that spent the last 4 days of culture in vivo also had relatively high rates of survival $(100 \%$ at $24 \mathrm{~h}, 73.7 \%$ at $72 \mathrm{~h})$. Consistent with previous observations, blastocysts produced entirely 


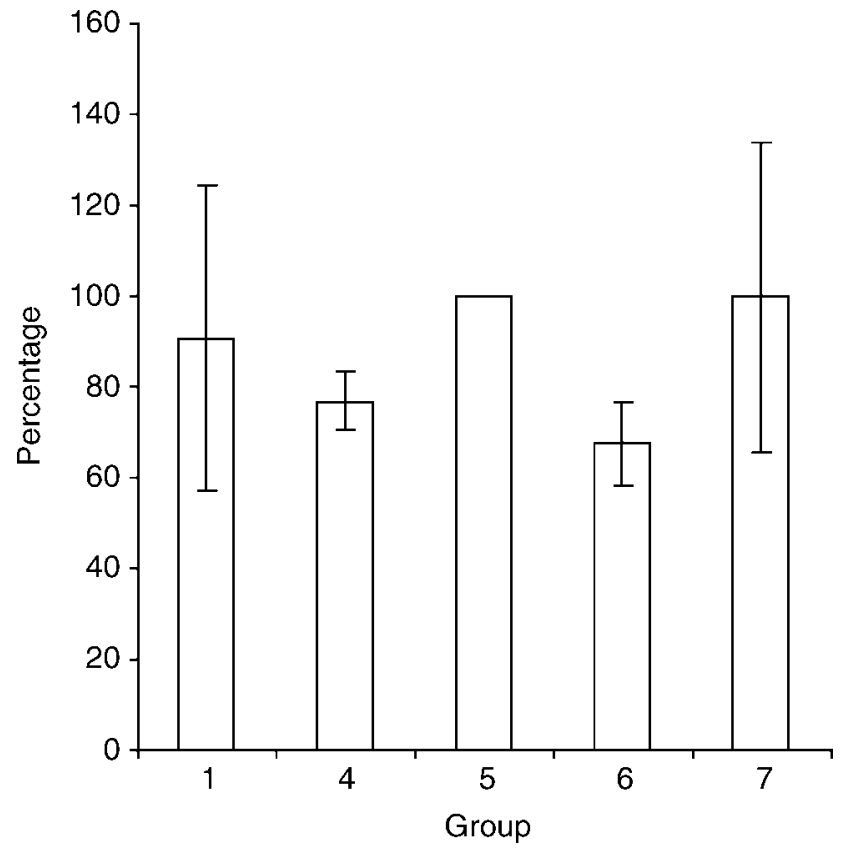

Fig. 5. Semi-quantitative RT-PCR of bovine L37 ribosomal protein. RT-PCRs were performed with the equivalent of one blastocyst from each group. Group 1: synthetic oviductal fluid (SOF) for 6 days; group 4: ewe oviduct for 2 days followed by culture in SOF for 4 days; group 5: ewe oviduct for 4 days followed by culture in SOF for 2 days; group 6: ewe oviduct for 6 days; and group 7: blastocysts were derived in vivo after superovulation and embryo recovery. The mean \pm SD was obtained from three independent RT-PCRs from different batches of blastocysts. The values for $\mathrm{L} 37$ were divided by the corresponding $\beta$-actin value (housekeeping gene, internal standard) and expressed relative to the highest sample signal set at $100 \%$. There were no significant differences between groups.

in SOF had very low rates of survival after vitrification, with $<40 \%$ viable at $24 \mathrm{~h}$ and $<20 \%$ survival at $72 \mathrm{~h}$. Blastocysts derived from embryos that spent the first 2 days in vivo and the last 4 days in vitro had the lowest rates of survival $(6.7 \%)$, whereas those that spent the last 2 days only in SOF had intermediate rates of survival $(40.6 \%)$. These data support the contention that some windows of embryo development are more predisposed to aberrant programming than others.

The data on cryotolerance were supported by observations of the relative abundance of gene transcripts in the blastocysts derived from the different groups. In particular, the relative abundance of transcripts for the cell death promoter, Bax, was significantly altered by modifying the culture environment. Consistent with previous observations (Rizos et al., 2002b), the expression of Bax was significantly higher in blastocysts derived from SOF than in those derived from culture in ewe oviduct or entirely in vivo. The ranking of the relative abundance of this transcript followed the same pattern as the cryotolerance results. Gjorret et al. (2001) reported that apoptosis is more frequent in blastocysts produced

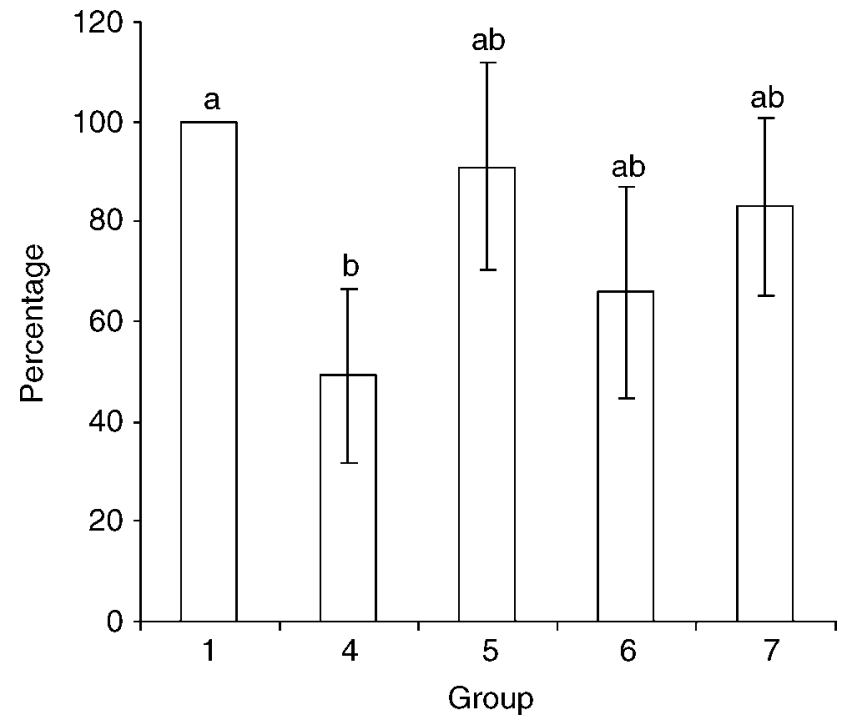

Fig. 6. Semi-quantitative RT-PCR of bovine S3a ribosomal protein. RT-PCRs were performed with the equivalent of one blastocyst from each group. Group 1: synthetic oviductal fluid (SOF) for 6 days; group 4: ewe oviduct for 2 days followed by culture in SOF for 4 days; group 5: ewe oviduct for 4 days followed by culture in SOF for 2 days; group 6: ewe oviduct for 6 days; and group 7: blastocysts were derived in vivo after superovulation and embryo recovery. The mean \pm SD was obtained from three independent RT-PCRs from different batches of blastocysts. The values for S3a were divided by the corresponding $\beta$-actin value (housekeeping gene, internal standard) and expressed relative to the highest sample signal set at $100 \%$. ${ }^{\text {ab }}$ Bars with different superscripts are significantly different $(P<0.05)$.

in vitro than those produced in vivo. Consistent with these observations, a higher incidence of apoptosis has been reported in blastocysts produced in vitro derived from late-cleaving zygotes than in those that cleave earlier (Byrne et al., 1999). Distortions of apoptosis in the blastocyst may lead to either early embryonic death or the formation of anomalies in the fetus that produce early abortions (Brill et al., 1999).

In contrast, expression of mRNA for ribosomal protein L37 behaved as a housekeeping gene; no correlation was found between embryo culture environment and pattern of gene expression. This finding is perhaps not surprising as ribosomal protein L37 shows constitutive expression in various mouse embryonic tissues; L37 is expressed constitutively even during transition from quiescence to active cell proliferation or terminal differentiation (Su and Bird, 1995).

Ribosomal protein S3a is located at the 40 S ribosomal subunit and is essential for initiation of translation (Westermann et al., 1981; Cramton and Laski, 1994). There is increasing evidence that ribosomal proteins are capable of extra-ribosomal functions. In many tumour cells, in which expression of ribosomal protein S3a is much higher than in normal cells, apoptosis could be induced by inhibiting S3a expression (Naora et al., 1998b). 
In stably transfected cell lines, up- and downregulation of S3a expression, coordinated in sequence, can actively induce apoptosis (Naora et al., 1998a). In bovine blastocysts produced in different culture environments, no correlation was found between S3a expression and treatment group. Although there were significant differences between some of the groups, these differences were not large and probably have no physiological importance.

There is some evidence in the literature to support the contention that embryos have temporal sensitivities to the culture environment. Although culture of ovine embryos with serum for 5 days resulted in oversized fetuses at day 125 of gestation, short-term exposure to serum either for the first 2 days or during the last 2 days of culture had no effect. Negrin-Pereira et al. (1997) performed an experiment involving culture for 2 days in either SOF plus serum or in co-culture, followed by culture for a further 3 days in the same or the alternative system. Their observations indicated that the developmental ability of the zygotes did not appear to be affected by the culture system used in the first 2 days, but the system used subsequently had a significant impact. In contrast, the results of the present study indicate that embryos cultured in SOF for 2 or 4 days before transfer to the sheep oviduct may be more sensitive to a change in their environment than those cultured in vivo for the initial 2 or 4 days and then cultured in vitro. This difference is difficult to explain but may relate to the vastly different culture environments in the two studies (ewe oviduct in this study versus co-culture in the study by Negrin Pereira et al., 1997). In another study from the present authors' group, it was shown that blastocysts produced in co-culture with granulosa cells had a higher cryotolerance than did those produced in SOF plus serum (Rizos et al., 2001); however, exposure to co-culture cells was necessary from day 3 onwards to acquire the improved cryotolerance.

Such evidence of temporal sensitivities of embryos has in part led to the production and commercialization of sequential media (Menezo et al., 1998). In addition, in human assisted reproduction, there is a move away from the transfer of early (day 2-3) embryos towards the transfer of blastocysts to: (i) identify the more developmentally competent embryos, as the poorer ones will not reach this stage; and (ii) to allow the transfer of fewer embryos, resulting in fewer multiple pregnancies (Menezo et al., 1998; Gardner et al., 2000). As shown in the present study, modification of the culture environment or inadequate culture conditions during the period of culture immediately after fertilization can result in severe consequences in terms of the normality of the blastocysts.

In conclusion, the results of the present study indicate that the conditions of embryo culture can have a marked effect on the quality of the resulting blastocyst and that bovine embryos show clear temporal sensitivity to their culture environment. The reduced cryotolerance of blastocysts generated in vitro is accompanied by alteration in mRNA expression of the Bax gene.
This work was supported by a grant from Science Foundation Ireland. J. Kanka, L. Nemcova and A. M. Mbaye were supported by a grant from the Grant Agency of the Czech Republic, no. 524/02/1135.

\section{References}

Abd El, Razek IM, Charpigny G, Kodja S, Marquant-Le Guienne B, Mermillod P, Guyader-Joly C and Humblot P (2000) Differences in lipid composition between in vivo- and in vitro-produced bovine embryos Theriogenology $\mathbf{5 3} 346$ (Abstract)

Boni R, Tosti E, Roviello S and Dale B (1999) Intracellular communication in in vivo- and in vitro-produced bovine embryos Biology of Reproduction 61 1050-1055

Brill A, Torchinsky A, Carp H and Toder V (1999) The role of apoptosis in normal and abnormal embryonic development Journal of Assisted Reproduction and Genetics 16 512-519

Byrne AT, Southgate J, Brison DR and Leese HJ (1999) Analysis of apoptosis in the preimplantation bovine embryo using TUNEL Journal of Reproduction and Fertility 117 97-105

Camous S, Kopecny V and Flechon JE (1986) Autoradiographic detection of the earliest stage of $\left[{ }^{3} \mathrm{H}\right]$-uridine incorporation into the cow embryo Biology of the Cell $\mathbf{5 8}$ 195-200

Cramton SE and Laski FA (1994) String of pearls encodes Drosophila ribosomal protein S2, has Minute-like characteristics, and is required during oogenesis Genetics 137 1039-1048

Duby RT, Hill JL, O'Callaghan D, Overstrom EW and Boland MP (1997) Changes induced in the bovine zona pellucida by ovine and bovine oviducts Theriogenology 47332 (Abstract)

Enright BP, Lonergan P, Dinnyes A, Fair T, Ward FA, Yang X and Boland MP (2000) Culture of in vitro produced bovine zygotes in vitro versus in vivo: implications for early embryo development and quality Theriogenology 54 659-673

Gardner DK and Lane M (1997) Culture and selection of viable blastocysts: a feasible proposition for human IVF? Human Reproduction Update 3 367-382

Gardner DK, Lane M and Schoolcraft WB (2000) Culture and transfer of viable blastocysts: a feasible proposition for human IVF Human Reproduction 15 Supplement 6 9-23

Gjorret JO, Avery B, Larsson L-I, Schelllander K and Hyttel P (2001) Apoptosis in bovine blastocysts produced in vivo and in vitro. Theriogenology 55321 (Abstract)

Kopecny V, Flechon JE, Camous S and Fulka J, Jr (1989) Nucleologenesis and the onset of transcription in the eight-cell bovine embryo: fine-structural autoradiographic study Molecular Reproduction and Development $\mathbf{1}$ 79-90

Lonergan P, Carolan C, Van Langendonckt A, Donnay I, Khatir H and Mermillod P (1996) Role of epidermal growth factor in bovine oocyte maturation and preimplantation embryo development in vitro. Biology of Reproduction 54 1420-1429

Lonergan P, Khatir H, Piumi F, Rieger D, Humblot P and Boland MP (1999a) Effect of time interval from insemination to first cleavage on the developmental characteristics, sex and pregnancy rates following transfer of bovine preimplantation embryos Journal of Reproduction and Fertility 117 159-167

Lonergan P, O'Kearney-Flynn M and Boland MP (1999b) Effect of protein supplementation and presence of an antioxidant on the development of bovine zygotes in synthetic oviduct fluid medium under high and low oxygen tension Theriogenology 51 1565-1576

McEvoy TG, Sinclair KD, Broadbent PJ, Goodhand KL and Robinson JJ (1998) Post-natal growth and development of simmental calves derived from in vivo or in vitro embryos Reproduction, Fertility and Development 10 459-464

McEvoy TG, Sinclair KD, Young LE, Wilmut I and Robinson JJ (2000) Large offspring syndrome and other consequences of ruminant embryo culture in vitro: relevance to blastocyst culture in human ART Human Fertility $3238-246$ 
Memili E and First NL (2000) Zygotic and embryonic gene expression in cow: a review of timing and mechanisms of early gene expression as compared with other species Zygote 8 87-96

Menezo YJR, Hamamah S, Hazout A and Dale B (1998) Time to switch from co-culture to sequential media for transfer at the blastocyst stage Human Reproduction 13 2043-2044

Naora H, Nishida T, Shindo Y and Adachi M (1998a) Antisense sequences of the nbl gene induce apoptosis in the human promyelocytic leukemia cell line HL-60 Leukemia 12 532-541

Naora H, Takai I and Adachi M (1998b) Altered cellular responses by varying expression of a ribosomal protein gene: sequential coordination of enhancement and suppression of ribosomal protein S3a gene expression induces apoptosis Journal of Cell Biology 141 741-753

Negrin Pereira N, McEvoy TG, Staines ME, King ME, Broadbent PJ, Mackie K, Ranilla M and Robinson JJ (1997) Effect of exposure to two different culture systems on the development and metabolism of in vivo derived sheep zygotes Theriogenology 47377 (Abstract)

Pollard JW and Leibo SP (1994) Chilling sensitivity of mammalian embryos Theriogenology 41 101-106

Rief S, Sinowatz F, Stojkovic M, Einspanier R, Wolf E and Prelle K (2002) Effects of a novel co-culture system on development, metabolism and gene expression of bovine embryos produced in vitro. Reproduction 124 $543-556$

Rizos D, Ward F, Boland MP and Lonergan P (2001) Effect of culture system on the yield and quality of bovine blastocysts as assessed by survival after vitrification Theriogenology 56 1-16

Rizos D, Lonergan P, Ward F, Duffy P and Boland MP (2002a) Consequences of bovine oocyte maturation, fertilization or early embryo development in vitro versus in vivo: implications for blastocyst yield and blastocyst quality Molecular Reproduction and Development $61234-248$

Rizos D, Lonergan P, Boland MP, Arroyo-Garcia R, Pintado B, de la Fuente J and Gutierrez-Adan A (2002b) Analysis of differential mRNA expression between bovine blastocysts produced in different culture systems: implications for blastocyst quality Biology of Reproduction $\mathbf{6 6}$ 589-595

Rizos D, Fair T, Papadopoulos S, Boland M and Lonergan P (2002C) Developmental, qualitative and ultrastructural differences between ovine and bovine embryos produced in vivo or in vitro. Molecular Reproduction and Development 62 320-327

Rizos D, Gutierrez-Adan A, Perez-Garnalo S, de la Fuente J, Boland MP and Lonergan P (2003) Bovine embryo culture in the presence or absence of serum: implications for blastocyst development, cryotolerance, and messenger RNA expression Biology of Reproduction 68 236-243
Scorano L, Oakes SA, Opferman JT, Cheng EH, Sorcinelli MD, Pozzan T and Korsmeyer SJ (2003) BAX and BAK regulation of endoplasmic reticulum $\mathrm{Ca}^{2+}$ : a control point for apoptosis Science 300 135-139

Slimane W, Heyman Y and Renard J-P (2000) Assessing chromosomal abnormalities by FISH analysis in 2-cell bovine embryos derived from in vitro and in vivo fertilization Theriogenology 53432 (Abstract)

Song DM, Sakamoto S and Taniguchi T (2002) Inhibition of poly(ADPribose) polymerase activity by $\mathrm{Bcl}-2$ in association with the ribosomal protein S3a Biochemistry 41 929-934

Su S and Bird RC (1995) Cell cycle, differentiation and tissue-independent expression of ribosomal protein L37 European Journal of Biochemistry 232 789-797

Vajta G, Holm P, Kuwayama M, Booth PJ, Jacobsen H, Greve T and Callesen H (1998) Open pulled straw (OPS) vitrification: a new way to reduce cryoinjuries of bovine ova and embryos Molecular Reproduction and Development $\mathbf{5 1}$ 53-58

Viuff D, Rickords L, Offenberg H et al. (1999) A high proportion of bovine blastocysts produced in vitro are mixoploid Biology of Reproduction $\mathbf{6 0}$ 1273-1278

Watson AJ (1992) The cell biology of blastocyst development Molecular Reproduction and Development 33 492-504

Westermann P, Nygard O and Bielka H (1981) Cross-linking of Met-tRNAf to elF-2 beta and to the ribosomal proteins S3a and S6 within the eukaryotic inhibition complex, elF-2.GMPPCP.Met-tRNAf.small ribosomal subunit Nucleic Acids Research 9 2387-2396

Wrenzycki C, Herrmann D, Carnwath JW and Niemann H (1999) Alterations in the relative abundance of gene transcripts in preimplantation bovine embryos cultured in medium supplemented with either serum or PVA Molecular Reproduction and Development 53 8-18

Wrenzycki C, Herrmann D, Keskintepe L, Martins A, Sirisathien S, Brackett B and Niemann H (2001) Effects of culture system and protein supplementation on mRNA expression in pre-implantation bovine embryos Human Reproduction 16 893-901

Young LE, Sinclair KD and Wilmut I (1998) Large offspring syndrome in cattle and sheep Reviews of Reproduction 3 155-163

Received 18 March 2003.

First decision 21 May 2003.

Revised manuscript received 9 June 2003.

Accepted 12 June 2003. 